\title{
Ambiguidades e conflitos da cultura patrimonializada no \\ espaço público: \\ o caso do candomblé em Salvador ${ }^{1}$
}

\author{
Ambiguities and conflicts of patrimonialized culture in public \\ space: \\ the case of Candomble in Salvador
}

Fátima Tavares ${ }^{2}$

Carlos Caroso ${ }^{3}$

Francesca Bassi ${ }^{4}$

\section{Resumo}

A configuração do candomblé no espaço público baiano é um exemplo instigante que sugere que sejam repensados os conceitos de religião e sociedade como domínios relacionais, que não se resolvem nas fronteiras de um espaço público demarcado pela laicidade. $\mathrm{O}$ argumento do texto desdobra-se em duas dimensões da mesma questão: por um lado evidenciamos a presença patrimonializada da cultura religiosa afro-brasileira em Salvador; e, por outro, as ambiguidades e conflitos que atravessam esses processos, visibilizando controvérsias religiosas na cultura afro-brasileira que contagiam as culturas urbanas daquela cidade. As circularidades dos símbolos do candomblé em Salvador e suas transgressões para além das fronteiras dos terreiros fazem emergir diferentes configurações do religioso num espaço público intensivo, no qual demarcações pregressas ou oficiais podem esvaziar-se de significado, produzindo arranjos e acomodações instáveis no pluralismo religioso local.

Palavras-chave: Candomblé; Espaço público; Patrimonialização; Controvérsias religiosas; Laicidade.

\footnotetext{
1 Uma versão preliminar deste texto foi apresentada no I Encontro Internacional de Cultura, Linguagens e Tecnologias do Recôncavo-ENICECUL (2017), no GT 6 - Diálogos interdisciplinares: memória, espaço e culturas.

2 Doutora em Ciências Humanas (Antropologia) pelo IFCS/UFRJ; Professora do Departamento de Antropologia e da Pós-Graduação em Antropologia da UFBA. Bolsista de Produtividade em Pesquisa do CNPq. Nível 2. E-mail: fattavares@ufba.br

${ }_{3}^{3} \mathrm{PhD}$ em Antropologia pela University of California, Los Angeles. Professor do Departamento de Antropologia e da Pós-Graduação em Antropologia da UFBA. Bolsista de Produtividade em Pesquisa do CNPq. Nível 1- B. E-mail: caroso@ufba.br

${ }_{4} \mathrm{PhD}$ em Antropologia pela Université de Montreal. Professora do Centro de Cultura, Linguagens e Tecnologia/UFRB. E-mail: f.yansa@gmail.br
} 
Religare, ISSN: 19826605, v.15, n.2, dezembro de 2018, p.526-547.

\section{Abstract}

The configuration of candomble in public space of Salvador is an instigating example that suggests the rethink the concepts of religion and society as relational domains, which cannot be solved within the borders of a public space demarcated by secularity. The argument of the text unfolds in two dimensions of the same question: on the one hand we called attention to the patrimonialisation of Afro-Brazilian religious culture in Salvador; and, on the other hand, the ambiguities and conflicts that cross these processes, bringing up to visibility the religious controversies present in the Afro-Brazilian culture which contaminates the urban cultures of that city. The circularities of the symbols of candomble in Salvador and their transgressions beyond the boundaries of the terreiros stimulates the emergence of different configurations of the religious in an intensive public space, in which previous or official demarcations can be emptied of meaning, producing unstable arrangements and accommodations in local religious pluralism.

Keywords: Candomblé; Public space; Patrimonialization; Religious controversies; Laicity.

\section{Introdução}

No presente artigo apresentamos alguns desafios que as religiões colocam para as configurações contemporâneas do espaço público. Contrariamente ao ideário de inexorabilidade da secularização, teorias mais recentes vêm evidenciando as diferentes modalidades empíricas desse processo nos contextos nacionais (CASANOVA, 2007; ASAD, 2003). Assim, ao invés de perguntamos acerca da maior ou menor presença da religião na sociedade, ganha relevância a problematização dos termos que permeiam e motivam esse debate: considerando-os não como essências, mas domínios relacionais, podemos rastrear as circularidades e "deslizamentos" dos conceitos de religião e espaço público, já que não estão "dados", mas configuram campos de forças que somente a posteriori emergem como "realidades" auto atribuídas5.

Nossa intenção é de evidenciar como essas delimitações conceituais são

\footnotetext{
${ }^{5}$ Como sugerem as abordagens antropológicas de Birman (2003), Camurça (2017), Giumbelli (2004, 2008, 2013), Montero (2006), Oro (2011), dentre outros, para o caso brasileiro.
} 
Religare, ISSN: 19826605, v.15, n.2, dezembro de 2018, p.526-547.

historicamente contingentes e, portanto, provisórias. Agenciamentos geralmente contidos em lugares de devoção, terreiros e templos também circulam "extramuros" provocando novas configurações. Assim, o que chamamos de

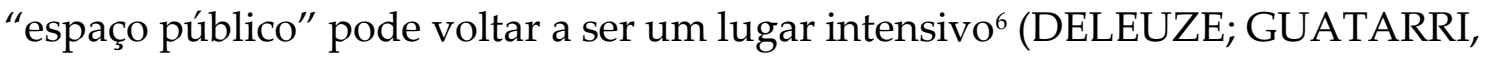
2000) no qual demarcações pregressas ou oficiais são esvaziadas de significados "originais": símbolos que foram reivindicados como específicos da "religião" de matriz africana, por exemplo, podem voltar a ser o cultural de "todos nós", ou, ainda, grupos religiosos evangélicos e católicos que pretendem legitimar uma relativa exclusão de outras religiosidades nos ambientes das cidades, contradizem ou combatem, mas também redefinem o que vem a ser a laicidade e pluralismo da gestão do espaço público.

A partir das orientações acima enunciadas, o texto é iniciado com uma discussão conceitual, problematizando as categorias de religião e sociedade, bem como sua regulação no contexto brasileiro por meio das disputas em torno da laicidade. A seguir discorremos sobre certas configurações dessa discussão para o contexto de Salvador, explorando a ideia do candomblé como cultura patrimonializada em suas ambiguidades e conflitos. Ao final apontamos alguns dilemas da dinâmica de visibilidade e invisibilidade das religiões afro-brasileiras, com laicidades em disputa na regulação do religioso no espaço público.

\section{Situando os conceitos}

Como argumenta Viveiros de Castro (2002, p. 300), o termo "sociedade" tem, no pensamento ocidental, sentidos diversos. Em acordo com a tradição iluminista (que se reflete na escola sociológica francesa), o conceito remete ao individualismo universalista (no sentido do princípio da cidadania que rompe com os laços originários de parentesco) e pode-se articular com a noção de societas, evocando o contrato social, o campo jurídico, político-institucional, a

\footnotetext{
${ }^{6}$ O lugar das intensidades, da propagação, do contágio, que é contrastado com o das características, dos perfis, em que se busca identificar diferenças e semelhanças.
} 
Religare, ISSN: 19826605, v.15, n.2, dezembro de 2018, p.526-547.

sociedade civil. Uma segunda acepção, que corresponde à reação romântica ao iluminismo (e ao pensamento antropológico alemão e a sua prossecução norteamericana), é definível com a noção de universitas, uma vivência comunitária operante como um todo orgânico, cuja origem comum substantivada no "sangue" (o parentesco) se reconhece a cada geração no simbólico e religioso compartilhado. Nesta segunda acepção, a sociedade coincide com o um particularismo cultural não generalizável, pois símbolos específicos (em vez do contrato social) garantem a integração dos seus membros.

$\mathrm{Na}$ atualidade podemos nos distanciar um pouco destas oposições e nos perguntarmos, como Viveiros de Castro o faz (2002, p. 315), se as neopragmáticas contemporâneas, que privilegiam os agentes em lugar de concepções estruturais de sociedade, podem relativizar estas dicotomias. O conceito de um "espaço público" remeteria então tanto a um ambiente físico (geralmente urbano) no qual símbolos culturais e religiosos transitam, como a um lugar mediado pela gestão institucional, dispondo-se como uma arena tanto para as expressões simbólicas, religiosas e comunitárias como para as possíveis legitimações institucionais. A questão que podemos colocar é se este seria um espaço multiverso, onde as configurações são promovidas a partir do momento em que novos agentes colocam em pauta novos estatutos de existência?

Garantir a permeabilidade desses conceitos nos possibilita compreender as religiões de forma aberta, em processo, fazendo-nos desconfiar dos lugares canônicos que possam produzir definições legítimas sobre o que seria um conceito "verdadeiro" de religião. Enquanto pesquisadores, temos que contornar esse caminho perigoso das teorias que produzem definições sobre as coisas do mundo, trazendo também as religiões para o contexto das controvérsias que reconfiguram seus mediadores legítimos e delineiam os contornos de um debate público. Tratando a questão desta maneira, pode-se dizer que aquilo que uma sociedade considera como "religião" aparece como um terreno provisório, movediço e sujeito permanentemente a ambiguidades e reconfigurações.

Em vista de recolocar processos contingentes que desmentem essências, 
Religare, ISSN: 19826605, v.15, n.2, dezembro de 2018, p.526-547.

vale lembrar que a atribuição de religião e sociedade a outrem não passou de uma projeção de atribuições próprias. Como escreve Gasbarro, a expansão ocidental foi tanto uma evangelização, em que os viajantes e os missionários estabeleceram com outrem relações (de poder) sub specie religionis (2011, p. 178), quanto uma missão "civilizatória" que comportou a etnocêntrica apreciação da vida coletiva de outrem a partir de qualidades societárias próprias. De fato, se houve oscilação entre conhecer as outras culturas em termos de religião ou de sociedade, é porque estes cortes são típicos de processos históricos ocidentais que culminaram com a moderna delimitação entre um campo de ação pública, laica e secularizada (norteada pelos direitos universais à cidadania) e o âmbito privado e confessional da religião (cristã e das outras "religiões" cuja liberdade de expressão é, como principio, um direito tutelado pelo Estado).

Na contemporaneidade, embora o principio da laicidade se faça presente como ideal, a regulação das relações entre Estado e religiões envolve variadas possibilidades na garantia do pluralismo e dos direitos de expressão das diversas religiões. Para o contexto brasileiro, conforme observado por Camurça (2017, p. 882), laicidade não significa ausência da religião no espaço público, pelo contrário: "[...] o termo "laicidade" no país parece funcionar mais como uma "referência" utilizada para tratar das relações entre religiões e Estado, referência esta sempre valorizada e adaptada aos interesses de cada um destes segmentos sociais, civil ou religioso". Camurça (op. cit.) prossegue por argumentar que, ao invés de princípios abstratos e de fronteiras precisas entre os domínios do secular e do religioso, temos controvérsias no espaço público que implicam em diferentes cenários de expansão e contenção da religião. Traçando algumas nuances dessa dinâmica, o autor recusa as análises dualistas nas relações entre o Estado e a esfera pública (como “contaminação”), seguindo a sugestão de Giumbelli (2013), de problematização dos modelos de laicidade e investimento nos processos que instituem essas relações. Reforçando seu argumento, ele apresenta dois vetores principais: no primeiro caso, de "expansão" do religioso, ações de ordem moral em temas controversos e de entronização de símbolos religiosos; no segundo, de 
Religare, ISSN: 19826605, v.15, n.2, dezembro de 2018, p.526-547.

"retração", ações para a retirada dos símbolos religiosos, além de iniciativa jurídico-legais contra a intolerância religiosa. No presente artigo interessa-nos observar de que forma as duas tendências podem coexistir na visibilização das religiões afro-brasileiras (leia-se o candomblé) no espaço público de Salvador, chamando a atenção para a dinâmica de "embaralhamentos" que marcam os processos empíricos, apontada pelo autor ao final do seu trabalho, e que vale a pena destacar em sua integralidade:

Portanto, como estas concepções de laicidade são sempre móveis e situadas, os quatro cenários - arenas ou configurações - que propus como instrumentos de análise podem ser embaralhados e permutados uns por outros: as ações religiosas que inibem políticas de direitos humanos revelam também a existência e visibilidade dessas iniciativas laicas; as ações para retirada de símbolos religiosos no espaço público não logram êxito com a permanência destes símbolos; a ocupação do cenário público por imagens religiosas implica também competição entre católicos e evangélicos, onde os evangélicos se unem aos laicos para contestar a ocupação católica, para, em seguida, estabelecerem com os católicos um acordo de repartição deste espaço público; a presença pública das religiões afro-brasileiras podem ser apoiadas enquanto direito à liberdade religiosa ou contestada por argumentos higienistas ou de "proteção dos animais" que provém do campo laico . Enfim, o que pode ser retração do religioso, por outro ângulo, pode significar expansão e viceversa. (CAMURÇA, 2017, p. 883)

Se, por um lado, a antropologia social e a ciência das religiões podem desconfiar hoje, depois de longa prática comparativa, da existência de fronteiras estáveis, capazes de delimitar religiões, esta postura acadêmica e os processos identitários (étnicos, mas também religiosos) não caminham sempre na mesma direção: parafraseando Carneiro da Cunha, pode-se escrever "religiões" (com aspas) para abraçar uma postura teórico-metodológico que indica como autoatribuições de qualidades religiosas (ou outras) dependem também de universos discursivos relativos a encontros e desencontros e à disputa de valores em pauta (CUNHA, 2009, p. 313). Como no caso de "culturas" que ressurgem, a despeito do conceito antropológico de cultura que vai sendo descreditado, vivências que 
Religare, ISSN: 19826605, v.15, n.2, dezembro de 2018, p.526-547.

outrora foram eminentemente étnicas passaram a se constituir como grupos organizados em comunidades "religiosas" - como sugere Parés (2006), as "nações" de Candomblé se formaram como recortes étnicos-políticos via expressões litúrgicas. Na contemporaneidade, as comunidades religiosas de matriz africana costuram/estabelecem novos diálogos com a esfera institucional, como demonstram as demandas de tombamento de terreiros (a Bahia é exemplar neste sentido). Demandas de legitimação deste tipo induzem a refletir sobre a maneira das religiões se articularem com "sociedades": a sociedade colonial, no caso da formação da religião denominada candomblé; a sociedade globalizada, que legitima direitos patrimoniais locais nos atuais tombamentos dos terreiros como patrimônio cultural e na visibilização da "cultura" afro-brasileira por meio das festas e monumentos espalhados pela cidade. Por outro lado, essa visibilidade, longe de configurar uma legitimação inconteste das religiões afrobrasileiras no espaço público, convive com fortes "entraves" na circulação dos seus símbolos religiosos, tendo que lidar recorrentemente com enfrentamentos religiosos (neopentecostais preponderantemente) e descaso do poder público. São os "embaralhamentos", apontados por Camurça, que complexificam os movimentos de expansão e recuo das religiões, implicando em práticas que tencionam as fronteiras entre uma gestão pública do espaço, que se pretende religiosamente neutra, e os anseios de visibilidade e reconhecimento institucional de ambientes e religiosos específicos, como veremos abaixo.

\section{Candomblé como cultura patrimonializada}

Seguindo a ideia de que "religiões" e "sociedades" se fazem mutuamente e que o espaço público no Brasil não é impermeável à regulação do religioso, apresentamos algumas pistas para se compreender a visibilidade pública do candomblé soteropolitano. Partimos do argumento de van de Port (2012) de que o candomblé está tanto dentro como fora dos cultos, dos terreiros, dos discursos sacerdotais, de que circula por muitos espaços e que vai se recriando nesse 
Religare, ISSN: 19826605, v.15, n.2, dezembro de 2018, p.526-547.

processo de conectar circuitos e produzir atalhos, de que os muitos lugares dos quais "o" candomblé "fala" não podem ser "classificados" a partir de métricas da tradição ou da legitimidade, mas que se trata justamente de investigar as formas pelas quais esses poderes se constituem (TAVARES, CAROSO, 2015).

Então, como nós, pesquisadores, podemos tornar produtivo um traçado de cartografias planas, no sentido de Latour (2006), por onde circulam as modalidades de se fazer o candomblé sem abraçar essencialismos, sem advogar versões mais ou menos autênticas, sem deixar de fora da investigação os interesses que são mobilizados nos diferentes circuitos por onde circula o candomblé? Podemos compreender sua circularidade na sociedade baiana por meio da fluidez das fronteiras entre os terreiros e outros circuitos da cidade, mas sem perder de vista as especificidades dos diferentes agentes envolvidos nesses processos? Agenciamentos religiosos (compreendendo também católicos e evangélicos), mas também políticos, artísticos e da gestão pública, apenas para mencionar os mais evidentes, vem transformando o candomblé em mais um aspecto da cultura urbana crescentemente patrimonializada. Ou seja, compreender o candomblé de Salvador é seguir essa circulação pela cidade transformando-a de várias maneiras e sendo transformada por esta mesma cultura.

Em Salvador (e cidade próximas), a visibilização do candomblé passa fortemente (mas não apenas) por sua transformação em "banco de símbolos" (como sugere van de Port) e também seu desdobramento em patrimônio cultural, com o tombamento de terreiros pelo IPHAN, IPAC e pelo Município de Salvador e a patrimonialização de festas e outros aspectos materiais e imateriais da cultura. São movimentos decorrentes das políticas oficiais de valorização da cultura negra que vêm se intensificando a partir do final dos anos de 1960 (SANTOS, 2005). Com o alargamento da noção de patrimônio para sua dimensão imaterial (Decreto 3.551, de 20007), observam-se importantes transformações que 
Religare, ISSN: 19826605, v.15, n.2, dezembro de 2018, p.526-547.

possibilitam a inclusão gradual dos bens culturais das populações minoritárias, ampliando o escopo do que se considerava como "bens culturais", que até então estavam centrados no patrimônio católico barroco (CAPONE, MORAES, 2015, p. 8).

Na década de 1980, no entanto, essa discussão ainda era muito incipiente, sendo o tombamento, pelo IPHAN, da Casa Branca, em 1984, um acontecimento marcante para as transformações posteriores. Como destacam Capone e Moraes (op. cit., p. 12), o parecer do antropólogo Gilberto Velho, consultor do IPHAN à época, encaminhado à Instituição, problematiza a noção de cultura vigente na patrimonialização, reivindicando a inclusão da dimensão imaterial que fundamente o sagrado. Pioneiro na modalidade de bem imóvel, o tombamento da Casa Branca dá início a uma nova forma de relação entre poder público e espaço religioso, com consequência poderosas sobre os processos de legitimação do candomblé em Salvador e no país (SERRA, 2005).

Capone e Moraes (op. cit., p. 14) destacam que esse pioneirismo ficou restrito à Casa Branca por muito tempo, já que o segundo tombamento de um terreiro pelo IPHAN, o Ilê Axé Opô Afonjá, só veio a ocorrer 15 anos após aquele primeiro. Até final do ano de $2017^{8}$ são identificados 13 terreiros tombados na cidade do Salvador: Casa Branca do Engenho Velho (IPHAN, 1984), Ilê Axé Opô Afonjá (IPHAN, 1999), Gantois (IPHAN, 2002), Bate Folha (IPHAN, 2003), Alaketo (IPHAN, 2004), Oxumaré (IPHAN, 2014), Pilão de Prata (IPAC, 2003) ${ }^{9}$, Mokambo - Onzó Nguzo Za Nkisi Dandalunda ye Tempo (IPAC, 2006), Ilê Axé Ibá Ogum (IPAC, 2007), Ilê Axé Kalé Bokún (IPAC, 2006), Tumba Junçara (IPAC, 2009), Ilê Asipá (IPAC, 2017) e do Hunkpame Savalu Vodun Zo Kwe, no Curuzu,

configura o conceito de "Registro" dos bens nos seguintes Livros: saberes (modos de fazer); celebrações (festas, rituais); formas de expressão (manifestações literárias, musicais, plásticas); lugares (espaços onde as práticas são executadas).

8 Segundo dados divulgados em sítio da internet do IPHAN, além de notícias veiculadas pela grande imprensa. No caso dos terreiros tombados pelo IPAC (Instituto do Patrimônio Artístico e Cultural da Bahia), existem algumas dissintonias entre as informações da grande imprensa e as disponibilizadas no sitio virtual da Instituição.

9 Todos os terreiros tombados pelo IPHAN, anteriormente mencionados, também foram tombados pelo IPAC. 
Religare, ISSN: 19826605, v.15, n.2, dezembro de 2018, p.526-547.

bairro da Liberdade (FGM, 2016) ${ }^{10}$. Isso não é muito, mas salta aos olhos de compararmos, por exemplo, com outros estados: apenas a Casa das Minas, no Maranhão, é tombada pelo IPHAN (MORAIS, 2015). No Rio de Janeiro foi realizado apenas um tombamento, o Ilê Axé Opô Afonjá, em São João de Meriti pelo Instituto Estadual do Patrimônio Cultural (INEPAC), no ano de 2016. Essa preponderância quantitativa de Salvador também pode explicar a realização pelo IPHAN do "I Curso de extensão Gestão e Salvaguarda do Patrimônio Cultural dos Terreiros Tombados" (em Salvador, em 2015), uma iniciativa que surgiu a partir das demandas de um Grupo de Trabalho, criado em 2015, reunindo representantes dos terreiros tombados. Uma das consequências do curso foi a criação, em 2017, da Comissão de Preservação e Salvaguarda dos Terreiros Tombados, formada pelos egressos.

A diversidade dos símbolos religiosos do candomblé de Salvador não se restringe ao espaço dos terreiros, mas "escorre" pela cidade, publicizando-se na plenitude do evento festivo ou em seus inúmeros "vazamentos" simbólicos, como a culinária, as danças, a estética das imagens. Atualmente, o sincretismo afro-católico mimetizado em patrimônio da cultura local soteropolitana aparece, por exemplo, o ofício das baianas de acarajé, registrado como patrimônio imaterial brasileiro em 2004, uma "cultura de rua", que implica na observância de várias dimensões da atividade, dentre elas o uso da indumentária religiosa típica do candomblé (BITTER, BITAR, 2012). O candomblé que se dissemina como cultura afro-católica também atravessa as "festas de largo"11 do verão soteropolitano, gerando polêmicas que se visibilizam no espaço público

\footnotetext{
10 Segundo o jornal A Tarde, foi a "primeira ação municipal da capital com base na Lei de Preservação do Patrimônio Cultural do Município (8.550/2014), de autoria do vereador Léo Prates (DEM). A ação foi executada pelo setor de patrimônio do município, criado neste ano, sob a responsabilidade da Fundação Gregório de Mattos (FGM)". Disponível em: http://atarde.uol.com.br/bahia/salvador/noticias/1739656-terreiro-vodun-zo-kwe-e-tombadopelo-municipio. Acesso em: 26 jun 2016.

11 As denominadas "festas de largo" são eventos festivos realizados em locais públicos, geralmente tendo uma praça (largo) como centro dos acontecimentos. São quase sempre eventos de cunho comemorativo ao dia dedicado a um santo católico. Nestas festas os aspectos sagrados e profanos são inseparáveis, conforme apontado por Serra (2009).
} 
Religare, ISSN: 19826605, v.15, n.2, dezembro de 2018, p.526-547.

especialmente durante a Festa do Bonfim (IPHAN, 2014), com a presença marcante de católicos e afro-brasileiros no cortejo da Lavagem (e também de evangélicos situados nas margens do cortejo), na festa de Santa Bárbara (IPAC, 2008), que conta com procissão e caruru e na festa de Iemanjá (em processo de registro pela lei municipal), para citarmos apenas as mais conhecidas, já que também ocorrem festas menos divulgadas pela mídia voltada para a promoção do turismo, como as festas de São Lázaro (janeiro) e de São Roque (agosto), que mobilizam mais intensamente as referências afro-religiosas. Enfim, são muitas mediações entre religião, espaço público e cidade sendo atualizadas por meio da festa "fazendo" religião e cultura. Através da patrimonialização das festas podese ainda perceber as transformações que marcam o panorama religioso de uma cidade como Salvador. No cenário contemporâneo, as festas baianas traduzem com intensidade a imbricação entre os aspectos religiosos e laicos da cultura, produzindo deslizamentos, zonas de superposição e sombra, resultando em fronteiras superpostas e borradas entre os dois tipos de fenômenos, transformando essas expressões religiosas em ícones da cultura local (SANSI, 2003).

Portanto, seguindo as pistas de Sansi (2007), ao invés de perguntamos se a cultura do candomblé em Salvador é autêntica ou se trata de uma "invenção" que mascararia os processos de dominação de segmentos subalternizados, podese rastrear essa história que fez do candomblé uma cultura objetificada. Com esse termo, o autor salienta que, ao considerar a cultura como "coisa", isso não significa deixar de lado a dimensão política. Pelo contrário, é precisamente essa a condição para a pluralidade de ações significativas: não podendo ser reduzida a uma reificação, compreende uma tessitura entre valores culturais (artísticos e antropológicos) com valores religiosos. 
Religare, ISSN: 19826605, v.15, n.2, dezembro de 2018, p.526-547.

\section{Candomblé e ambiguidades da cultura}

As relações entre cultura, religiões e espaço público, enquanto cultura objetificada (ao menos em Salvador) e pour cause, implicam em ambiguidades na confrontação de valores diferenciados, especialmente nas relações entre sujeitos e objetos, conforme aponta Sansi (2005). Tomemos como caso paradigmático o processo de tombamento do Terreiro da Casa Branca para evidenciar as ambiguidades entre cultura patrimonializada e conflitos no espaço público que atravessa o cotidiano dos terreiros. Serra (2005) chama a atenção para os poucos trabalhos que se debruçam sobre as dificuldades de gerenciamento e manutenção do território. Neste texto, que apresenta em detalhes o processo de tombamento da Casa Branca, o autor articula duas questões: a) a importância do conceito de “territórios negros" (p. 169, nota 1) para se compreender as dinâmicas das religiões-afro brasileiras nas cidades contemporâneas; b) as transformações, na década de 1980, que produzem um novo momento nas relações entre terreiros e Estado na promoção dos bens culturais do candomblé. O autor vai delineando essa confluência no contexto de Salvador, quando menciona a iniciativa, em 1981, de mapeamento dos principais sítios e monumentos religiosos da Bahia (Projeto MAMNBA), conduzido por três instituições: Fundação Nacional Pró-Memória (FNPM), a Prefeitura Municipal do Salvador e a Fundação Cultural do Estado da Bahia. No documento inicial do projeto Serra destaca a importância dos terreiros não apenas por serem templos religiosos, como também por seu papel de aglutinador e integrador de comunidades negras e negro-mestiças, tal como destacado abaixo:

[...] além de representarem centros religiosos, os terreiros vêm a ser uma forma de assentamento de populações pobres, negras ou negro-mestiças, tanto em Salvador como em outras urbes brasileiras: assentamentos com um arranjo específico, com um tipo de manejo característico de seu espaço, de seu entorno. Sublinhou-se no referido texto o imperativo de levar em consideração esse tipo especial de assentamento no planejamento urbano da metrópole baiana. Insistiu-se também 
Religare, ISSN: 19826605, v.15, n.2, dezembro de 2018, p.526-547.

na categorização dos sítios em apreço como bens de cultura dignos de preservação. (SERRA, 2005, p. 172)

A iniciativa de reconhecimento do território do terreiro como espaço religioso possibilitada pelo mapeamento então em curso foi fundamental para as reorientações que a Casa Branca apresentaria na tentativa de resolução dos conflitos territoriais que o terreiro vinha experimentado por muitos anos: cobrança de arrendamento, instalação de um posto de combustíveis em parte da área da "Praça de Oxum", e que chegara ao clímax por ocasião da tentativa, por parte do proprietário, de implantação de edifícios multiresidenciais na área. Conforme detalhado pelo autor, esse conflito ganha episódios de visibilidade nacional, tendo sido vitorioso o pleito da comunidade religiosa, requalificando a forma como os gestores públicos lidam com o patrimônio afro-religioso ${ }^{12}$. As estratégias iniciais de defesa do território por meio do instituto do usucapião, assim como da isenção do Imposto Predial e Territorial Urbano (IPTU) não foram possíveis em decorrência da "inadequação" às normas legais de ocupação do solo urbano, característica muito frequente desses templos religiosos ${ }^{13}$. A proposta dos membros do Projeto MAMNBA propiciou um deslocamento decisivo na estratégia de enfrentamento, imbricando os direitos ao território à religião e à cultura patrimonializada. Reivindicação que foi efetivada inicialmente por decreto municipal, em agosto de 1982, que "tombou" o terreiro (mesmo sem contar com um livro de tombo de monumentos, como esclarece o autor) e, dois anos depois, após intensos debates, campanhas e discordâncias de parte do corpo técnico da Instituição, com o tombamento pelo IPHAN.

\footnotetext{
${ }^{12}$ Mais recentemente, as estratégias de musealização no espaço de algumas das casas tradicionais de Salvador vêm incrementando as iniciativas de patrimonialização da cultura afro-brasileira: Museu Ilé Ohum Lalai (Ilê Axé Opô Afonjá), ainda na década de 1980; Memorial Mãe Menininha (Gantois), em 1992; Memorial Lajoumim (Terreiro Pilão de Prata), em 1994 e Memorial Kissimbiê (Terreiro Mukambo). Sobre essa questão, ver, dentre outros, Sörensen (2015), Gama (2018)

${ }_{13}$ Conforme esclarece o autor (p. 176-177), o primeiro caso, do usucapião, não era possível, pois pagava-se o arredamento ao proprietário até pouco tempo antes desse processo; no segundo caso, a ausência de documento de posse do terreno inviabilizava a solicitação da isenção do IPTU. Sobre o impacto das transformações urbanas no candomblé de Salvador, ver Rego (2008).
} 
Religare, ISSN: 19826605, v.15, n.2, dezembro de 2018, p.526-547.

No entanto, é preciso ressaltar que embora Salvador concentre o maior número de terreiros de candomblé tombados no país, ainda assim, trata-se de uma parcela ínfima das casas existentes, tendo em vista o grande número de terreiros na cidade (SANTOS, 2008). A patrimonialização de algumas casas consideradas "tradicionais", conforme aponta Morais (op. cit.) decorre de processos de grande negociação e reconhecimento, mas sabemos que se trata de uma gota num oceano de vulnerabilidades históricas. Esse incipiente processo de patrimonialização não deve mascarar, portanto, os muitos conflitos que atravessam o cotidiano tanto das casas tombadas, mas provavelmente muito mais daquelas não tombadas. A permanência dos imóveis do espaços religiosos tensiona-se crescentemente com as políticas públicas de ocupação do solo urbano, razão pela qual muitas delas se encontram envolvidas em disputas territoriais, com severas ameaças a sua estrutura física, como foi o caso do Oyá Onipo Neto, parcialmente destruído em 2008 por ação de agentes de órgão municipal (PIRES, 2008; SILVA, 2018).

A visibilidade do candomblé na cidade também compreende uma circularidade de disputas, ressignificações e ambiguidades da cultura que "vazam" dos terreiros em controvérsias religiosas. Assim, certos espaços públicos geram polêmicas de maior repercussão midiática, como a dos orixás do Dique do Tororó (de autoria do artista plástico Tati Moreno), inaugurados em abril de 1998. Conforme apresentado em detalhes por Sansi (2005), este episódio envolveu intensas manifestações de evangélicos ligados à Igreja Universal do Reino de Deus, ocasionando tentativas de destruição física do monumento. Embora, à época, o conflito tenha sido resolvido por meio da intervenção de Antônio Carlos Magalhães, com a IURD reconhecendo seu "erro" de tomar os orixás como fetiche e não como arte pública (SANSI, 2005), lances subsequentes desdobram-se em novas controvérsias sobre o Dique do Tororó. Estas oscilam entre projetos que pretendem retirar os orixás (do candidato a deputado federal Pastor Elionai Muralha, do PRTB, conforme noticiado pelo Jornal A Tarde (16/09/2014) e da vereadora Cátia Rodrigues (PHS), que ressuscita uma ideia do 
Religare, ISSN: 19826605, v.15, n.2, dezembro de 2018, p.526-547.

deputado estadual Pastor Sargento Isidório (PSC) e propõe a colocação de monumento representando a Bíblia no Dique do Tororó (Jornal A Tarde, 04/09/2015). São polêmicas que nos dão ideia do quanto podem ser instáveis os "acordos" na relação entre patrimonialização da(s) religião(ões) no espaço público e modernização urbana.

A visibilização das disputas religiosas tem lugar com novos objetos e espaços da cidade, como nas polêmicas em torno da "Pedra de Xangô" ou Otá de Xangô ${ }^{14}$, situada no "miolo" da cidade, no bairro de Cajazeiras X. Desde a abertura de uma avenida (Av. Assis Valente) nas redondezas, em 2005, foi exposta a enorme pedra de 27 metros de diâmetro que era tradicionalmente utilizada como espaço ritual do povo de santo. Em 2014, houve uma profanação desse espaço ritual com pichações, depósito de sal grosso (200 kg, segundo notícias veiculadas nos jornais) e destruição das oferendas, fatos esses que vieram fortalecer o movimento em torno do tombamento do sítio de importância religiosa afro-baiana. Em dezembro do mesmo ano foi realizada uma caminhada na Pedra de Xangô em repúdio aos atos de vandalismo cometido contra lugares sagrados para o povo de santo.

Em fevereiro de 2016, durante a realização da VII Caminhada da Pedra de Xangô, uma manifestação anual de resistência aos atos de intolerância religiosa que compreende a realização de um cortejo que se desloca do início da Avenida Assis Valente até o local (Jornal Correio, 13/02/2017), onde ocorrem apresentações de rodas de capoeira e um xirê, foi anunciado pelo presidente da Fundação Gregório de Mattos que o tombamento da pedra se daria até julho de 2016, sendo efetivamente realizado em maio de 2017. No depoimento de mãe Iara, destacado pelo jornal (Jornal Correio, 04/05/2017) que noticiou o tombamento, evidenciamse as tensões entre transformações do espaço urbano e prática do candomblé: "Há oito anos, lutamos por isso, com a criação da Associação Parque das Águas e com a Caminhada da Pedra de Xangô, que teve a primeira edição em 2010. Antes, isso

\footnotetext{
${ }^{14}$ As notícias na impressa local sobre essa Pedra de Xangô também fazem referência a um certo quilombo de Orubu, situado na região.
} 
Religare, ISSN: 19826605, v.15, n.2, dezembro de 2018, p.526-547.

aqui era tudo mata fechada, mas começaram a vir moradores, invasões e muito descaso". Sendo o terceiro bem tombado pelo município ${ }^{15}$, a área de 17 hectares onde está situada a Pedra foi oficializada como APA (Área de Proteção Ambiental), com a futura construção de um parque com equipamentos urbanos e local para cerimônias religiosas (Jornal Correio, 04/05/2017).

Em outro ponto da cidade, mais delicada é a situação atual dos adeptos das religiões afro-brasileiras que tinham no ambiente e recursos do Parque de São Bartolomeu, situado no subúrbio ferroviário de Salvador, os espaços sacralizados de vivência e realização de rituais de sua religião. Como constata Santos (2016) em seu estudo que resultou na Dissertação de Mestrado, a intervenção do poder público no Parque com o propósito de requalificá-lo, ao contrário do que havia sido acordado com os moradores do local e seus frequentadores, resultou não apenas no deslocamento físico de grande parte dos que ali habitavam, de templos religiosos de matriz afro-brasileira, e estabelecimentos comerciais nos quais as pessoas retiravam o sustento das famílias, como a nova ordem higiênica implantada tornou a colocação de oferendas aos orixás e outras práticas não são mais benvindas no lugar que, ironicamente, nomeia sua principal praça como "Praça de Oxum". A questão que podemos levantar sobre a proposta de intervenção do poder público no Parque da Pedra de Xangô é exatamente se aquele será palco das mesmas controvérsias, já que o planejamento urbano nem sempre leva em conta, ou mesmo desconhece, os significados imanentes às especificidades e peculiaridades culturais de cada segmento da população, mais das vezes, guiando-se por ideologias e diretrizes modernizantes e excludentes gestadas em escolas que não valorizam as peculiaridades culturais, mas, ao contrário, tomam os modelos exógenos como dogmas a serem seguidos.

\footnotetext{
${ }^{15}$ Segundo noticiou o Jornal Correio, de 04/05/2017, os outros dois são o terreiro do Curuzu e a estátua do Cristo no bairro da Barra, desconsiderando, portanto, o "tombamento" da Casa Branca.
} 
Religare, ISSN: 19826605, v.15, n.2, dezembro de 2018, p.526-547.

Devemos ainda observar que as regulações do religioso no espaço público não se limitam aos lugares públicos e as relações entre sujeitos e objetos, mas atravessam os processos patrimonializados da cultura imaterial. Controvérsias religiosas marcam as reconfigurações do tradicional cortejo da Lavagem do Bonfim, com maior visibilização de rituais católicos nos últimos anos. Como aponta Ramos (2017), desde 2009 observa-se a introdução de uma benção católica, idealizada pelo então Reitor do Santuário, Padre Edson Menezes, realizada em frente à Igreja, no ápice do cortejo. Em 2014, foi adotada outra “inovação" conduzida pelo mesmo religioso, conforme destaca a autora: "[...] um evento denominado 'Lavagem do Corpo e da Alma', um cortejo alternativo ao oficial sem a presença das baianas. A partida da Conceição da Praia [início do cortejo], inclusive, acontece horas antes do [cortejo] oficial." (p. 143).

Da mesma forma, como aponta Évora (2015), o patrimônio imaterial do ofício das baianas de acarajé também tem sido objeto de controvérsias na medida em que suas origens como "comida de santo", outrora comercializado por mulhrees que ganhavam as ruas da cidade do Salvador com seus tabuleiros de comida sobre a cabeça apregoando "acarajé eko", como forma de chamamento aos fregueses diários Todo este patrimônio vem sendo questionado por vendedoras de acarajé16 convertidas à religiões evangélicas. A recusa nessa associação entre comida e candomblé é o que mobiliza a utilização (ainda que discreta) de símbolos cristãos nos tabuleiros (adesivos religiosos e a bíblia), além da retirada de certas "marcas" na indumentária característica de baianas, como os colares, ou guias, que associam a pessoa aos Orixás, ou mesmo a recusa completa do traje por algumas vendedoras evangélicas, e, o mais marcante, é a ressignificação da linguagem com relação ao tradicional bolinho de feijão frito no azeite de dendê que é amplamente conhecido como acarajé, que recebe a redenominação de "bolinho de Jesus". Assim, como observado pela autora, a

\footnotetext{
16 É importante registrar que Costa Lima (2010) distingue o acarajé sagrado, dedicado e consumido pelos Orixás e outras entidades do Candomblé, daquele que é comercializado como mercadoria nas ruas de Salvador e outras cidades da Bahia.
} 
Religare, ISSN: 19826605, v.15, n.2, dezembro de 2018, p.526-547.

preocupação reinante é como estes eventos podem trazer consequências para esse ofício, considerando a patrimonialização da cultura em suas relações com o candomblé, o que pode ser ilustrado pela citação abaixo cotejada de seu texto:

Em 2011, uma nova preocupação surgiu para a ABAM [Associação Nacional das Baianas de Acarajé], em consequência da não utilização da indumentária típica pelas baianas de acarajé nas ruas de Salvador. O IPHAN lhes enviou, por meio de oficio, um alerta sobre o risco da perda do título de patrimônio imaterial em razão da descaracterização do ofício das baianas, constatado nas ruas de Salvador. (ÉVORA, 2015, p. 48)

\section{Concluindo}

Dessencializar as relações entre religião e espaço público faz parte de um rol de desafios que inclui também as consequências do nosso papel enquanto pesquisadores na produção de relatos no mundo e não "sobre" o mundo. Pois nossos relatos também fazem o mundo, juntamente com a infinidade heterogênea das contribuições dos nossos contemporâneos e predecessores. O mundo, como aponta Latour (2012), pode ser conceitualmente compreendido como o "social": conceito cobiçado e que, ao contrário do que o senso comum imagina, não está dado de uma vez por todas, mas é sempre o resultado provisório dos agrupamentos que o delineiam. O que chamamos de "sociedade" e "natureza" são resultados de um agrupamento do social, iniciados pelas ciências sociais no final do século XIX e consolidado no século XX. Seguindo Latour de perto, esse desenho não nos serve nos dias atuais, sendo necessário ampliar os novos vínculos e agrupamentos que surgem; precisamos rever o repertório dos agentes e das forças que tornam os "novos atores" compreensíveis. Para isso, temos desafios na ciência e na política, coisas que também imaginamos separadas, como na promessa weberiana. No caso que nos interessa, o que a antropologia pode fazer para reagregar o espaço público cada vez mais povoado pela diversidade religiosa? 
Religare, ISSN: 19826605, v.15, n.2, dezembro de 2018, p.526-547.

Retornando ao argumento central de van de Port, a ideia de que em Salvador o candomblé está em todos os lugares não significa uma indistinção entre os circuitos, ou seja, é preciso reconhecer os diferentes agenciamentos que o candomblé opera. Considerar o candomblé como “banco de símbolos” apenas, é deixar de fora duas dimensões importantes nas relações entre religiões e espaço público: a) a especificidade da mediação operada pela religião, que compreende modos de agenciamento que transformam as práticas e não apenas símbolos estabilizados que circulam por diferentes contextos do espaço público; b) as diferentes modalidades (política, jurídica e outras) pelas quais se atualizam as controvérsias públicas.

Com relação aos agenciamentos religiosos, é preciso rastrear a dinâmica entre circularidade (dos "símbolos") e produção da diferença (especificidade dos agenciamentos religiosos) no candomblé, "para dentro" e "para fora" dos terreiros, mas também "entre" os terreiros. Isso porque a própria configuração do(s) candomblé(s) se encontra pontuada pela relação controversa entre diferentes terreiros, onde se imbricam proximidades (de iniciação religiosa, parentesco, amizade, etc.) e evitações; práticas colaborativas e concorrenciais. No âmbito dessas controvérsias é preciso levar em conta o imaginário de segredos, perigos e "exoticidade" construído em torno do candomblé para considerar as suas formas específicas de circularidade pelo espaço público local.

Com relação às modalidades por onde circulam as controvérsias públicas, parece-nos adequado falar em "laicidades em disputa", que atravessa os órgãos institucionais de patrimonialização (IPAC, IPHAN) é um contraponto desafiador para a religião (sem aspas). De fato, a lógica interna da religião não coincide com a lógica patrimonializada da "religião" como projeto (inter) cultural, ainda menos quando se trata de religiões baseadas no proselitismo. As contradições logo se desdobram no âmbito político. A política cultural inspirada pelo pensamento laico internacional na valorização da diversidade (vale mencionar as diretrizes da Unesco) faz reagir as políticas locais interpenetradas pelos fundamentalismos das religiões evangélicas; por outro lado, reagem os 
Religare, ISSN: 19826605, v.15, n.2, dezembro de 2018, p.526-547.

candomblecistas, que devem se contrastar à hostilidade evangélica e construir estratégias de sobrevivência no combate contra intolerância religiosa reconfigurando-se, defensivamente, como "religião", devendo agora definir argumentos ritualísticos e religiosos num implícito dialogo contra a condenação (SILVA, 2007) $)^{17}$.

\section{Referências}

ASAD, Talal. Formations of the secular. Stanford: Stanford University Press, 2003. BIRMAN, Patricia, et al. Religião e espaço público. São Paulo: Attar Editorial, 2003. BITTER, Daniel; BITAR, Nina Pinheiro. Comida, trabalho e patrimônio: notas sobre o ofício das baianas de acarajé e das tacacazeiras. Horizontes Antropológicos, v. 18, n.38, 2012, p. 213-236.

CAMURÇA, Marcelo Ayres. A questão da laicidade no Brasil: mosaico de configurações e arena de controvérsias. Horizonte. Revista de Estudos de Teologia e Ciências da Religião. V. 15, n. 47, 2017, p. 855-886.

CAPONE, Stefania e MORAIS, Mariana R. de. De la négation à l'affirmation: le processus d'institutionnalisation du patrimoine culturel afro-brésilien. Afropatrimoines Culture afro-brésilienne et dynamiques patrimoniales. Les Carnets Du Lahic. n. 11, 2015, p. 6-24.

CASANOVA, José. Rethinking secularization: A global comparative perspective. In: Religion, globalization, and culture. Brill, 2007. p. 101-120. Disponível em: https://www.researchgate.net/profile/Jose_Casanova7/publication/265540966_R ethinking_Secularization_A_Global_Comparative_Perspective/links/552cdd270 cf2e089a3acfae0/Rethinking-Secularization-A-Global-Comparative-

Perspective.pdf. Acesso em: 25. jul. 2018.

Deleuze Gilles; GUATARRI, Felix., Mil platôs: capitalismo e esquizofrenia. Editora 34; 2000.

COSTA LIMA, Vivaldo da. A anatomia do acarajé e outros escritos. Salvador: Corrupio, 2010.

CUNHA, Manuela. Cultura com aspas. São Paulo: Cosac Naify, 2009.

ÉVORA, Lígia. Do acarajé ao bolinho de Jesus. In: TAVARES, Fátima; GILBELLI, Emerson (Orgs.). Religiões e temas de pesquisa contemporâneos: diálogos antropológicos. Salvador: EDUFBA, 2015, p. 33-52.

\footnotetext{
${ }^{17}$ Mais recentemente, vale também lembrar os argumentos de condenação relativos aos sacrifícios de animais, e aos movimentos defensivos dos pais e das mães de santo em prol da legitimação dos seus hábitos religiosos.
} 
Religare, ISSN: 19826605, v.15, n.2, dezembro de 2018, p.526-547.

GAMA, Elizabeth C. Lugares de memórias do povo-de-santo: patrimônio cultural entre museus e terreiros. Tese (doutorado em história) Universidade Federal Fluminense: Niterói/RJ, 2018.

GASBARRO, Nicola. Qual comparação em História das Religiões segundo LéviStrauss?. Rever. v. 11, n. 1, 2011, p. 166-183.

GIUMBELLI, Emerson. Religião, estado, modernidade: notas a propósito de fatos provisórios. Estudos Avançados. v. 18, n. 52, 2004, p. 47-52.

A presença do religioso no espaço público: modalidades no Brasil. Religião E sociedade. v. 28, n.2, 2008, p. 80-101.

Para estudar a laicidade, procure o religioso. In: BÉLIVEAU, Verónica Giménez; GIUMBELLI, Emerson (Orgs.). Religión, Cultura e política en las Sociedades del siglo XXI. Buenos Aires: Biblos, 2013. p. 43-68.

LATOUR, Bruno. Reagregando o social: uma introdução à teoria do ator-rede. Salvador: Edufba, 2012.

MONTERO, Paula. Religião, pluralismo e esfera pública no Brasil. Novos EstudosCEBRAP. n. 74, 2006, p. 47-65.

MORAIS, Mariana. Les religions afro-brésiliennes en tant que patrimoine: du conflit à l'institutionnalisation. Afro-patrimoines Culture afro-brésilienne et dynamiques patrimoniales. Les Carnets Du Lahic. n. 11, 2015, p. 98-118.

ORO, Ari Pedro. A laicidade no Brasil e no Ocidente. Algumas considerações. Civitas. v. 11, n. 2, 2011, p. 221-237.

PARÉS, Luis Nicolau. História e ritual da nação Jêje na Bahia. Campinas/SP: Editora Unicamp, 2006.

PIRES, Álvaro Roberto. A hora de rodar a baiana! Preservação das matrizes de origem africana na religiosidade brasileira contra a intolerância. Revista África e Africanidades. n. 2, 2008, p. 82-95.

RAMOS, Cleidiana. Festa de verão em Salvador. Um estudo antropológico a partir do acervo documental do jornal A Tarde. Tese (Doutorado em antropologia). Programa de Pós-Graduação em Antropologia. Universidade Federal da Bahia. Salvador, 2017.

REGO, Jussara. Territórios do candomblé: a desterritorialização dos terreiros na Região Metropolitana de Salvador, Bahia. GeoTextos. v. 2, n. 2, 2008, p. 31-85.

SANSI, Roger. De imagens religiosas a ícones culturais: reflexões sobre as transformações históricas de algumas festas públicas na Bahia. In: BIRMAN, Patrícia (Org.). Religião e espaço público. São Paulo: Attar Editorial, 2003, p. 149-68. . Fetiches e monumentos: arte pública, iconoclastia e agência no caso dos "orixás" do dique de Itororó. Religião \& Sociedade. v. 25, n. 2, 2005, p. 6281.

Fetishes and monuments: Afro-Brazilian art and culture in the 20th century. New York: Berghahn Books, 2007.

SANTOS, Jocélio Teles dos. O poder da cultura e a cultura no poder: a disputa simbólica da herança cultural negra no Brasil. Salvador: Edufba, 2005.

. Mapeamento dos terreiros de Salvador. Salvador: UFBA,

Centro de Estudos Afro-Orientais, 2008. 
Religare, ISSN: 19826605, v.15, n.2, dezembro de 2018, p.526-547.

SANTOS, Lucia. Presas com Mel e Dendê: Memórias dos deslocados do Parque Metropolitano de São Bartolomeu. Dissertação (Mestrado em Antropologia). Universidade Federal da Bahia, 2016.

SERRA, Ordep. Monumentos negros: uma experiência. Afro-Ásia. n. 33, 2005, p. 169-205.

2009. . Rumores de festa: o sagrado e o profano na Bahia. Salvador: EDUFBA,

SILVA, Vagner Gonçalves da. Neopentecostalismo e religiões afro-brasileiras: Significados do ataque aos símbolos da herança religiosa africana no Brasil contemporâneo. Mana. v. 13, n. 1, 2007, p. 207-236.

SILVA, Gilda. O drama do terreiro Oyá Onípo Neto: análise etnográfica dos diferentes discursos dos atores sociais envolvidos no caso de 2008. Trabalho de Conclusão de Curso (Graduação em Ciências Sociais). Universidade Federal da Bahia: Salvador, 2018.

SÖRENSEN, Sheiva. De tombamentos e museus. Estratégias político-culturais no candomblé de Salvador. Dissertação (Mestrado em Antropologia). Universidade Federal de São Carlos: São Carlos/SP, 2015.

TAVARES, Fátima; CAROSO, Carlos. Candomblé (s) e espaço público na ilha de Itaparica, Bahia. Religião e Sociedade. v. 35, n. 2, 2015, p. 297-318.

VAN de PORT, Matthijs. Candomblé em Rosa, Verde e Preto. Debates do NER. n. 22, 2012, p. 123-164.

VIVEIROS DE CASTRO, Eduardo. A inconstância da alma selvagem. São Paulo: Cosac Naify, 2002.

Recebido em 29-08-2018. Aprovado em 20-01-2019. 